\title{
EFFECT OF PREOPERATIVE INTRAVENOUS CLONIDINE ON HEMODYNAMIC RESPONSE DURING LAPAROSCOPIC SURGERIES
}

Sreeraghu G. ${ }^{1}$, Hemanth Kumar J²

\section{HOW TO CITE THIS ARTICLE:}

Sreeraghu G. M, Hemanth Kumar J. "Effect of Preoperative Intravenous Clonidine on Hemodynamic Response during Laparoscopic Surgeries". Journal of Evolution of Medical and Dental Sciences 2014; Vol. 3, Issue 08, February 24; Page: 1885-1894, DOI: 10.14260/jemds/2014/2074

BACKGROUND AND OBJECTIVES: Laparoscopy is a minimally invasive procedure used as a diagnostic and therapeutic tool for abdominal and pelvic pathologies. Laparoscopy offers many benefits compared to open surgeries, but it leads to increase in stress hormones, increased peripheral vascular resistance and decreased cardiac output causing hemodynamic fluctuation. In addition, ventilatory changes and increases in partial pressure of carbon dioxide also occur during laparoscopic surgeries due to pneumoperitoneum. To overcome these hemodynamic effects of insufflation various methods have been used like combined epidural with general anesthesia, propofol infusion, high dose of opioids, beta blockers, nicardipine, oral clonidine etc. In this study, we used intravenous clonidine as premedication to suppress these changes. METHODS: After obtaining ethical committee clearance and informed consent from patient, we enrolled 60 adult patients, aged between 20-60 years, of ASA grade 1 and 2 posted for laparoscopic intra-abdominal surgeries. The patients were divided into 2 groups of 30 each randomly, viz: Group C Study group: Injection clonidine, $2 \mathrm{mcg} / \mathrm{kg}$, as premedication was given intravenously, $15 \mathrm{~min}$ prior to induction of anesthesia. Group $\mathbf{N}$ Control group: received injection normal saline, 5cc, intravenously. For both the groups same type of anesthesia and analgesia was given. Heart rate, blood pressure, mean arterial pressure were recorded in both groups. Sedation, incidence of post-operative nausea vomiting after extubation were also observed. Statistical analysis was done using student T test and P value obtained. RESULTS: In the present study, decreases in heart rate, systolic, diastolic and mean arterial blood pressures were noticed in the clonidine group. Inspite of maintaining normocapnia and keeping intra-abdominal pressure below $14 \mathrm{mmm}$ of $\mathrm{Hg}$ significant rises in heart rate, systolic, diastolic and mean arterial blood pressures were noticed in the control group. CONCLUSION: From this study, we conclude that intravenous clonidine $2 \mathrm{mcg} / \mathrm{kg}$, given $15 \mathrm{~min}$ prior to induction provides stable hemodynamics and protection against stress response to intubation and carbon dioxide insufflation in patients undergoing laparoscopic surgeries. Clonidine provides the added advantages of reduction in postoperative complications of nausea, vomiting and shivering.

KEYWORDS: ANETHESIA, LAPAROSCOPY, CLONIDINE, HEMODYNAMIC.

INTRODUCTION: Laparoscopy is a minimally invasive procedure used as a diagnostic and therapeutic tool for abdominal and pelvic pathologies. There are a number of advantages to the patient with laparoscopic surgery over the conventional laparotomy technique. These include shorter hospital stay, rapid return to normal activities, less pain and smaller incisions. ${ }^{1}$

During laparoscopic procedures, abdominal organs are visualized by intra-abdominal insufflation of carbon dioxide. The use of pneumoperitoneum in combination with positional changes may cause significant hemodynamic and respiratory changes. ${ }^{2}$ These changes are considered to be 
mediated by mechanical and neurohumoral factors. Catecholamine, renin angiotensin system and vasopressin are released during pneumoperitoneum. ${ }^{2}$

To overcome these hemodynamic effects of insufflation various methods have been used like combined epidural with general anesthesia, propofol infusion, high dose of opioids, beta blockers, nicardipine, oral clonidine etc.

In this study, we used intravenous clonidine as premedication to suppress these changes. Clonidine is an alpha 2 adrenergic agonist known to cause suppression of outflow of sympathetic nervous system. ${ }^{3-5}$

In addition, clonidine attenuates the stress response to intubation. ${ }^{2,5-7}$ It is also beneficial in preventing postoperative nausea and vomiting (PONV) and shivering8 in the postoperative period.

MATERIALS AND METHODS: The present study is a randomized controlled trial. After obtaining ethical committee clearance and informed consent from patient, we enrolled 60 adult patients, aged between 20-60 years, of ASA grade 1 and 2 posted for laparoscopic intra-abdominal surgeries. The patients were divided into 2 groups of 30 each randomly, viz:

Group C Study group: Injection clonidine, $2 \mathrm{mcg} / \mathrm{kg}$, as premedication was given intravenously, 15 min prior to induction of anesthesia.

Group N: Control group- received injection normal saline, 5cc, intravenously.

For both the groups same type of anesthesia and analgesia was followed.

\section{EXCLUSION CRITERIA:}

1. Patients with ASA 3 or 4 grade.

2. Patients less than 20 years and more than 60 years of age.

3. Pregnant and nursing women.

4. Patients on beta blockers.

BEFORE SURGERY: Standard anesthetic technique was followed in both the groups.

Premedication: Inj. Clonidine $2 \mathrm{mcg} / \mathrm{kg}$, slow intravenous, given $15 \mathrm{~min}$ prior to induction in Group C.

\section{DURING SURGERY:}

\section{Preinduction:}

- Intravenous Ondansetron $4 \mathrm{mg}$

- Intravenous Fentanyl 2mcg/kg

- Intravenous Midazolam $0.03 \mathrm{mg} / \mathrm{kg}$

\section{General anesthesia was given with:}

Induction: With injection Propofol $2 \mathrm{mg} / \mathrm{kg}$.

Intubation: Under effect of injection Rocuronium $1 \mathrm{mg} / \mathrm{kg}$

Maintenance: $\mathrm{O}_{2}+$ Air + Isoflurane + Rocuronium intermittent bolus muscle relaxant.

\section{Intraoperative Monitoring:}

Pulse rate, Blood pressure, $\mathrm{SpO}_{2}, \mathrm{ETCO}_{2}$ were monitored intraoperatively. 


\section{Reversal:}

After surgery patients were reversed with injection Neostigmine, $0.04 \mathrm{mg} / \mathrm{kg}$ with injection Glycopyrrolate, $0.01 \mathrm{mg} / \mathrm{kg}$ body weight intravenous, slowly.

OBSERVATION AND RESULTS: Observation and results were obtained from the two groups by statistical analysis with paired and unpaired $T$ tests and calculating the $\mathrm{p}$ value.

$\mathrm{p}>0.05$ was considered as not significant.

$\mathrm{p}<0.05$ was considered as significant

$\mathrm{p}<0.01$ was considered as highly significant.

\begin{tabular}{|l|c|c|c|c|}
\hline \multirow{2}{*}{ Parameter } & \multicolumn{4}{|c|}{ Study drug (n=30) } \\
\cline { 2 - 5 } & Mean \pm SD & Min & Max & Median \\
\hline Age & $36.9 \pm 11.9$ & 21.0 & 58.0 & 34.5 \\
\hline Weight & $52.7 \pm 6.7$ & 43.0 & 70.0 & 51.5 \\
\hline \multicolumn{1}{|c|}{ Sex } & $\mathbf{N}$ & \% & - & - \\
\hline Male & 08 & 26.66 & - & - \\
\hline Female & 22 & 73.33 & - & - \\
\hline
\end{tabular}

Table 1: Demographic Data of the Patients- Study Group

The mean age in study group was $36.9 \pm 11.9$ years and mean weight was $52.7 \pm 6.7 \mathrm{~kg}$. There were 8 males and 22 females in the study group.

\begin{tabular}{|l|c|c|c|c|}
\hline \multirow{2}{*}{ Parameter } & \multicolumn{4}{|c|}{ Control drug (n=30) } \\
\cline { 2 - 5 } & Mean \pm SD & Min & Max & Median \\
\hline Age & $35.6 \pm 12.5$ & 21.0 & 60.0 & 30.5 \\
\hline Weight & $55.17 \pm 9.6$ & 42.0 & 78.0 & 54.5 \\
\hline \multicolumn{1}{|c|}{ Sex } & N & \% & - & - \\
\hline Male & 10 & 66.66 & - & - \\
\hline Female & 20 & 33.33 & - & - \\
\hline
\end{tabular}

Table 2: Demographic Data of the Patients- Control Group

The mean age in control group was $35.6 \pm 12.5$ years and mean weight was $55.17 \pm 9.6 \mathrm{~kg}$. There were 10 male and 20 female in the control group. 


\section{ORIGINAL ARTICLE}

\begin{tabular}{|l|c|c|c|c|c|c|}
\hline \multirow{2}{*}{ HR } & \multicolumn{3}{|c|}{$\begin{array}{c}\text { Study drug } \\
\text { (n=30) }\end{array}$} & \multicolumn{3}{c|}{$\begin{array}{c}\text { Control drug } \\
\text { (n=3) }\end{array}$} \\
\cline { 2 - 7 } & Mean \pm (SD & $\begin{array}{c}\text { \% change } \\
\text { from Baseline }\end{array}$ & $\begin{array}{c}\text { p } \\
\text { value }\end{array}$ & Mean \pm SD & $\begin{array}{c}\text { change } \\
\text { from Baseline }\end{array}$ & $\begin{array}{c}\text { p } \\
\text { value }\end{array}$ \\
\hline Pre-0p & $88.2 \pm 14.6$ & 0.0 & & $87.8 \pm 7.2$ & 0.0 & - \\
\hline Before induction & $89.0 \pm 14.5$ & 0.9 & 0.539 & $81.9 \pm 7.4$ & 5.0 & $<0.001$ \\
\hline After intubation & $91.4 \pm 10.7$ & 3.5 & 0.158 & $96.9 \pm 6.7$ & 19.7 & $<0.001$ \\
\hline $\mathrm{CO}_{2}$ insufflation & $89.4 \pm 13.1$ & 1.4 & 0.525 & $89.4 \pm 7.5$ & 13.0 & $<0.001$ \\
\hline 5 min after insufflations & $88.2 \pm 14.2$ & 0.0 & 0.988 & $90.3 \pm 8.4$ & 13.9 & $<0.001$ \\
\hline 15 min after insufflations & $88.7 \pm 10.5$ & 0.5 & 0.819 & $89.9 \pm 8.0$ & 13.4 & $<0.001$ \\
\hline 30 min after insufflations & $87.9 \pm 11.2$ & -0.3 & 0.912 & $88.1 \pm 8.4$ & 11.7 & $<0.001$ \\
\hline 60 min after insufflations & $87.3 \pm 12.0$ & -1.0 & 0.712 & $90.5 \pm 8.6$ & 14.0 & $<0.001$ \\
\hline 90 min after insufflations & $89.3 \pm 13.3$ & 1.2 & 0.667 & $89.1 \pm 8.8$ & 12.7 & $<0.001$ \\
\hline 120 min after insufflations & $89.1 \pm 10.8$ & 1.0 & 0.723 & $89.1 \pm 9.3$ & 12.6 & $<0.001$ \\
\hline After CO ${ }_{2}$ desufflation & $90.5 \pm 11.1$ & 2.6 & 0.339 & $90.9 \pm 9.4$ & 14.4 & $<0.001$ \\
\hline
\end{tabular}

Table 3: Change in Heart Rate in Study and Control Groups

Statistical analysis with paired t test was done. There was no significant percentage change in heart rate from the baseline $(\mathrm{p}>0.05)$ throughout the procedure in the study group.

In the control group, the percentage increase in the heart rate from the baseline was maximum after intubation $(19.7 \%)$ and it was highly significant $(\mathrm{p}<0.01)$. The percentage change in the heart rate remained elevated from the baseline throughout the procedure and was highly significant $(\mathrm{p}<0.01)$.

\begin{tabular}{|l|c|c|c|c|}
\hline \multirow{2}{*}{ Systolic Blood Pressure } & Study drug (n=30) & Control drug (n=30) & p & Significance \\
\cline { 2 - 5 } & Mean \pm SD & Mean \pm SD & value & \\
\hline Pre-Op & $124.1 \pm 11.7$ & $119.5 \pm 9.1$ & 0.097 & NS \\
\hline Preinduction & $120.5 \pm 14.5$ & $118.2 \pm 7.6$ & 0.438 & NS \\
\hline After intubation & $122.5 \pm 16.2$ & $135.0 \pm 12.1$ & 0.001 & HS \\
\hline $\mathrm{CO}_{2}$ insufflation & $116.2 \pm 13.2$ & $132.2 \pm 11.1$ & 0.001 & HS \\
\hline 5 min after insufflation & $117.2 \pm 14.5$ & $132.5 \pm 9.2$ & 0.001 & HS \\
\hline 15 min after insufflation & $113.6 \pm 11.9$ & $136.5 \pm 10.1$ & 0.001 & HS \\
\hline 30 min after insufflation & $112.5 \pm 10.3$ & $130.7 \pm 6.5$ & 0.001 & HS \\
\hline 60 min after insufflation & $112.1 \pm 12.2$ & $130.2 \pm 6.6$ & 0.001 & HS \\
\hline 90 min after insufflation & $112.8 \pm 13.2$ & $130.1 \pm 6.1$ & 0.001 & HS \\
\hline 120 min after insufflation & $113.2 \pm 12.8$ & $129.7 \pm 5.7$ & 0.001 & HS \\
\hline After desufflation & $115.0 \pm 12.2$ & $126.1 \pm 9.0$ & 0.001 & HS \\
\hline \multicolumn{2}{|l|}{ Table 4: Comparison of Systolic Blood Pressures in Patients of Study and Control Groups }
\end{tabular}

NS-Not significant, HS-Highly significant

Statistical analysis with unpaired t test was done. Results showed that in the preoperative and preinduction periods there was no statistically significant ( $p>0.05)$ difference in systolic blood pressures in the two groups. After intubation, carbon dioxide insufflation, at $5 \mathrm{~min}, 15 \mathrm{~min}, 30 \mathrm{~min}$, $60 \mathrm{~min}, 90 \mathrm{~min}, 120 \mathrm{~min}$ and after carbon dioxide desufflation, the statistical difference in two groups 
was highly significant $(\mathrm{p}<0.01)$ with a significant increase in the mean systolic blood pressures in the control group.

\begin{tabular}{|l|c|c|c|c|}
\hline \multirow{2}{*}{ Diastolic Blood Pressure } & Study drug (n=30) & Control drug (n=30) & P & \multirow{2}{*}{ Significance } \\
\cline { 2 - 3 } & Mean \pm SD & Mean \pm SD & 0.2407 & NS \\
\hline Pre-Op & $82.7 \pm 8.8$ & $80.4 \pm 6.2$ & 0.2321 & NS \\
\hline Preinduction & $79.3 \pm 11.1$ & $82.3 \pm 7.6$ & 0.0111 & HS \\
\hline After intubation & $82.1 \pm 10.9$ & $88.9 \pm 9.3$ & 0.001 & HS \\
\hline $\mathrm{CO}_{2}$ insufflation & $78.4 \pm 9.1$ & $87.4 \pm 6.5$ & 0.0001 & HS \\
\hline 5 min after insufflation & $80.9 \pm 11.4$ & $89.3 \pm 7.4$ & 0.0013 & HS \\
\hline 15 min after insufflation & $77.5 \pm 8.8$ & $87.9 \pm 4.5$ & 0.0001 & HS \\
\hline 30 min after insufflation & $77.6 \pm 6.5$ & $89.5 \pm 3.5$ & 0.0001 & HS \\
\hline 60 min after insufflation & $77.4 \pm 8.6$ & $92.1 \pm 5.0$ & 0.0001 & HS \\
\hline 90 min after insufflation & $77.3 \pm 9.0$ & $90.7 \pm 6.4$ & 0.0001 & HS \\
\hline 120 min after insufflation & $79.2 \pm 9.1$ & $89.3 \pm 5.0$ & 0.0001 & HS \\
\hline After desufflation & $79.2 \pm 9.8$ & $86.2 \pm 7.8$ & 0.0034 & . \\
\hline
\end{tabular}

Table 5: Comparison of Diastolic Blood Pressure in Patients of Study and Control Groups

NS-Not significant, HS-Highly significant

Statistical analysis with unpaired t test was done. Results showed that in the preoperative and preinduction periods, there was no statistically significant difference $(p>0.05)$ in the diastolic blood pressure in the two groups. After intubation, carbon dioxide insufflation, $5 \mathrm{~min}, 15 \mathrm{~min}, 30 \mathrm{~min}, 60$ min, $90 \mathrm{~min}, 120 \mathrm{~min}$ and after carbon dioxide desufflation, the statistical difference in the two groups was highly significant $(\mathrm{p}<0.01)$ with a significant increase in the mean diastolic blood pressure in the control group.

\begin{tabular}{|l|c|c|c|c|}
\hline \multirow{2}{*}{ Mean } & Study drug $(\mathbf{n = 3 0 )}$ & Control drug (n=30) & P & \multirow{2}{*}{ Significance } \\
\cline { 2 - 3 } & Mean \pm SD & Mean \pm SD & & \\
\hline Pre-Op & $96.8 \pm 9.8$ & $94.1 \pm 6.1$ & 0.2034 & NS \\
\hline Preinduction & $94.4 \pm 11.5$ & $93.6 \pm 6.6$ & 0.7324 & NS \\
\hline After intubation & $96.0 \pm 13.1$ & $104.1 \pm 8.2$ & 0.0059 & HS \\
\hline $\mathrm{CO}_{2}$ insufflation & $90.4 \pm 9.9$ & $102.4 \pm 7.6$ & 0.0001 & HS \\
\hline 5 min after insufflation & $93.1 \pm 13.4$ & $103.5 \pm 7.5$ & 0.0005 & HS \\
\hline 15 min after insufflation & $89.7 \pm 9.5$ & $103.7 \pm 4.7$ & 0.0001 & HS \\
\hline 30 min after insufflation & $89.7 \pm 7.4$ & $102.7 \pm 3.8$ & 0.0001 & HS \\
\hline 60 min after insufflation & $89.0 \pm 9.3$ & $104.7 \pm 5.0$ & 0.0001 & HS \\
\hline 90 min after insufflation & $89.1 \pm 9.9$ & $103.1 \pm 5.2$ & 0.0001 & HS \\
\hline 120 min after insufflation & $90.6 \pm 10.1$ & $102.3 \pm 4.8$ & 0.0001 & HS \\
\hline After $\mathrm{CO}_{2}$ desufflation & $91.0 \pm 10.0$ & $99.3 \pm 7.8$ & 0.0007 & HS \\
\hline
\end{tabular}

\section{Table 6: Comparison of Mean Blood Pressures in Patients of Study and Control Groups}

NS-Not significant, HS-Highly significant 
Statistical analysis with unpaired t-test was done. Results showed that in preoperative and preinduction periods, there was no statistically significant ( $p>0.05)$ difference in the mean blood pressures in the two groups. After intubation, carbon dioxide insufflation, $5 \mathrm{~min}, 15 \mathrm{~min}, 30 \mathrm{~min}, 60$ min, $90 \mathrm{~min}, 120 \mathrm{~min}$ and after carbon dioxide desufflation, the statistical difference in the two groups was highly significant $(\mathrm{p}<0.01)$, with a significant increase in the mean blood pressure in the control group.

\begin{tabular}{|l|c|c|c|}
\hline \multicolumn{1}{|c|}{ Side Effects } & $\begin{array}{c}\text { Study drug } \\
(\mathbf{n = 3 0 )}\end{array}$ & $\begin{array}{c}\text { Control drug } \\
(\mathbf{n = 3 0 )}\end{array}$ & $\begin{array}{c}\text { P } \\
\text { value }\end{array}$ \\
\hline Urinary retention & $1(3.33 \%)$ & 0 & 1 \\
\hline $\begin{array}{l}\text { Sedation } \\
\text { (Ramsay score 2-3) }\end{array}$ & $6(20 \%)$ & 0 & 0.0237 \\
\hline Shivering & $2(6.66 \%)$ & $9(30 \%)$ & 0.0419 \\
\hline PONV & $1(3.33 \%)$ & $6(20 \%)$ & 0.1028 \\
\hline \multicolumn{4}{|r}{ Table 7: Side Effects }
\end{tabular}

The table shows side effects in both study and control groups. $20 \%$ of the patients in the study group were well sedated with significant $p$ value $(0.0237)$. A high incidence of shivering (30\%) with significant $p$ value of $(0.0419)$ and PONV (20\%) was seen in the control group.

DISCUSSION: Laparoscopic surgery has a long and colorful history since its origin in 1901 by Kelling. ${ }^{9}$ Laparoscopic cholecystectomy was first performed by Philip Mouret in 1987.10

Laparoscopy offers many benefits compared to open surgeries, but it leads to increase in stress hormone responses (cortisol, epinephrine and norepinephrine), increased peripheral vascular resistance and decreased cardiac output causing hemodynamic fluctuation. In addition, ventilatory changes and increases in partial pressure of carbon dioxide also occur during laparoscopic surgeries due to pneumoperitoneum. ${ }^{2}$ All these changes have been studied by various authors over the last decade.

Mealy K, Gallagher H et al (1992) ${ }^{11}$ studied the physiologic and metabolic responses to open and laparoscopic cholecystectomy. Deterioration in perioperative respiratory function was significantly less for laparoscopic surgery. Arterial blood gas determinations indicated a greater perioperative decrease in arterial $\mathrm{pH}$. Hormonal profile changes demonstrated an increase in urinary vanillylmandelic acid in the laparoscopic cholecystectomy group; no differences were detected in urinary cortisol, metanephrine or nitrogen excretion. Acute phase response was greatest in patients undergoing open cholecystectomy as determined by erythrocyte sedimentation rate (ESR) and Creactive protein (CRP) level. These data indicate improved respiratory and subjective response and diminished acute phase response associated with laparoscopic surgery. Catabolic hormone release may, however, be increased.

Westerband A, Van De Water J, et al (1992) ${ }^{12}$ studied the cardiovascular changes in laparoscopic cholecystectomy in 16 patients and concluded that a decrease of $30 \%$ in the cardiac index (CI) and 5\% in the heart rate (HR), along with an increase of $15 \%$ in mean arterial pressure (MAP) and 79\% in the calculated total peripheral resistance index occurred. This elevation in after load can lead to an increase in myocardial oxygen demand and potential risk of myocardial ischemia or cardiac failure in susceptible individuals. 
Cunningham AJ et al (1993) ${ }^{13}$ measured cardiovascular changes associated with the reverse Trendelenburg position during laparoscopic cholecystectomy using transoesophageal echocardiography. End tidal carbon dioxide $\left(\mathrm{EtCO}_{2}\right)$ values increased after insufflation of carbon dioxide with values significantly higher after lateral tilt positioning. Creation of pneumoperitoneum was associated with an increase in left ventricular end systolic wall stress concomitant with increases in peak airway pressure and mean arterial pressure. In addition, the left ventricular end diastolic area decreased after reverse Trendelenburg positioning. Left ventricular ejection fraction was maintained throughout the study.

Wakizaka $Y$ et al (1994) ${ }^{14}$ studied the effects of carbon dioxide insufflation during laparoscopic cholecystectomy on the arterial blood gases and $\mathrm{pH}$. They observed that insufflation of carbon dioxide causes large change in $\mathrm{PaCO}_{2}$ and $\mathrm{pH}$ in patients who had a history of major cardiac or respiratory disease. They also showed that low insufflation pressures and short duration of surgery is beneficial for the maintenance of a normal physiological state.

In recent years, laparoscopic surgery has become a common clinical practice. Pneumoperitoneum required for laparoscopic surgery produces significant hemodynamic changes, which can be detrimental especially in elderly and hemodynamically compromised patients. ${ }^{15}$ Various techniques and pharmacological agents have been used to counteract the hemodynamic effects of pneumoperitoneum.

We evaluated the efficacy of intravenous clonidine in maintaining the hemodynamic stability during laparoscopic surgery.

Clonidine is a centrally acting alpha 2 agonist initially used as an antihypertensive drug. It is a highly lipid soluble drug and easily crosses blood brain barrier. It causes a reduction of tonic sympathetic outflow and decrease in blood pressure and heart rate. It attenuates hypertension, tachycardia and norepinephrine release in response to stress induced by anesthetic and surgical procedures. $^{3}$

The present study was conducted in 60 adult patients. They were divided into 2 groups, study and control, with 30 patients in each, belonging to ASA grade $1 \& 2$. The study group received injection clonidine $2 \mathrm{mcg} / \mathrm{kg}$ intravenously, 15 minutes prior to induction and the control group received normal saline. Intraoperative monitoring of heart rate, blood pressure and $\mathrm{EtCO}_{2}$ was done. In the post-operative period, we observed patients for occurrence of complications like excess sedation, nausea, vomiting and shivering.

In the present study, the mean heart rate was $88.2 \pm 14.6 \mathrm{bpm}$ in the preoperative period in the study group. In the control group it was $87.8 \pm 14.6 \mathrm{bpm}$. There was $3.5 \%$ increase in heart rate after intubation, in the study group whereas, in the control group it increased by $19.7 \%$, which is highly significant $(\mathrm{P}<0.01)$. This change in heart rate remained increased throughout the procedure in control group while it remained close to baseline in study group (Table-3). Our findings are similar to study conducted by, Mirinmoy Das, Manjushree Ray, Gauri Mukherjee.6 In their study they have shown, that there was significant rise in heart rate in control group while heart rate remained towards baseline in the clonidine group.

In the present study, there was no statistically significant difference in systolic blood pressure in the two groups ( $\mathrm{p}>0.05)$ during preoperative and preinduction periods. The statistical difference in the two groups was highly significant after intubation, carbon dioxide insufflation, $5 \mathrm{~min}, 15 \mathrm{~min}$, $30 \mathrm{~min}, 60 \mathrm{~min}, 90 \mathrm{~min}, 120 \mathrm{~min}$ after insufflation and after desufflation $(\mathrm{p}<0.01)$ with significant 
increase in mean systolic blood pressure in the control group. The mean systolic blood pressure in preoperative period was $124 \pm 11.7 \mathrm{~mm}$ of $\mathrm{Hg}$ in the study group and $119.5 \pm 9.1 \mathrm{~mm}$ of $\mathrm{Hg}$ in the control group. In the study group, the mean systolic blood pressure remained less than the baseline throughout the study. There was $1.3 \%$ fall in mean systolic blood pressure from baseline after intubation. In control group, the mean systolic blood pressure remained elevated from the baseline throughout the study. There was $11.5 \%$ increase in the mean systolic blood pressure from the baseline after intubation (Table-4).

In the present study, there was no statistically significant difference in the diastolic blood pressure in the two groups during preoperative and preinduction periods ( $>>0.05)$. The statistical difference in two groups was highly significant after intubation, carbon dioxide insufflation, 5 min, 15 $\mathrm{min}, 30 \mathrm{~min}, 60 \mathrm{~min}, 90 \mathrm{~min}, 120 \mathrm{~min}$ and after desufflation $(\mathrm{p}<0.01)$ with significant increase in diastolic blood pressure in control group. The mean diastolic blood pressure in pre-operative period was $82.7 \pm 8.8 \mathrm{~mm}$ of $\mathrm{Hg}$ in the study group and $80.4 \pm 6.2 \mathrm{~mm}$ of $\mathrm{Hg}$ in the control group. In the study group, there was $0.7 \%$ fall in the mean diastolic blood pressure from the baseline after intubation. The mean diastolic blood pressure remained less than the preoperative period throughout the procedure, whereas in the control group there was $9.6 \%$ increase in mean diastolic blood pressure from the baseline after intubation. The mean diastolic blood pressure remained elevated from the baseline throughout the procedure (Table-5).

In the present study, there was no statistically significant difference in the mean arterial blood pressure in the two groups during preoperative and preinduction periods $(p>0.05)$. The statistical difference in two groups was highly significant after intubation, carbon dioxide insufflation, $5 \mathrm{~min}, 15 \mathrm{~min}, 30 \mathrm{~min}, 60 \mathrm{~min}, 90 \mathrm{~min}, 120 \mathrm{~min}$ and after desufflation $(\mathrm{p}<0.01)$ with significant increase in mean arterial blood pressure in control group. The mean arterial blood pressure in preoperative period was $96.8 \pm 9.8 \mathrm{~mm}$ of $\mathrm{Hg}$ in the study group and $94.1 \pm 6.1 \mathrm{~mm}$ of $\mathrm{Hg}$ in the control group. In the study group, there was $0.8 \%$ fall in the mean arterial blood pressure from the baseline after intubation. The mean arterial blood pressure remained less than the baseline throughout the study, whereas in control group, there was $9.6 \%$ increase in the mean arterial blood pressure from the baseline after intubation. The mean arterial blood pressure remained elevated from the baseline throughout the study (Table-6).

Sunita Goel, Manju Sinha3, in their study have shown that there was a significant fall in the systolic, diastolic and mean arterial blood pressures in the clonidine group while there was a significant increase in the control group with significant inter group comparison.

In a similar study by Mirinmoy Das, Manjushree Ray, Gauri Mukherjee 6, a significant increase in systolic, diastolic and mean blood pressure in the control group throughout the intraoperative period from the baseline was seen. In the clonidine group they found that the patients remained hemodynamically stable.

In the present study, decreases in heart rate, systolic, diastolic and mean arterial blood pressures were noticed in the clonidine group. Inspite of maintaining normocapnia and keeping intra-abdominal pressure below $14 \mathrm{mmm}$ of $\mathrm{Hg}$ significant rises in heart rate, systolic, diastolic and mean arterial blood pressures were noticed in the control group. This suggests that clonidine premedication provides perioperative hemodynamic stability.

In the postoperative period, we observed patients for the occurrence of complications like excessive sedation, nausea, vomiting and shivering. 
We evaluated sedation with the Ramsay sedation score and found that the sedation score was higher in the study group compared to the control group. $20 \%$ patients in the study group had a sedation score between 2 and 3 as compared to a sedation score of 1 to 2 in the control group. This showed that patients in the study group were more comfortable and pain free as compared to the control group (Table 7).

Sunita Goel, Manju Sinha ${ }^{3}$ concluded that the sedation, analgesic sparing and anxiolytic effects of clonidine offer a distinct advantage.

In the present study, we found that the incidence of shivering in the study group was $6.6 \%$, while in the control group it was 30\% (Table 7). This shows that clonidine has additional advantage of preventing shivering in the postoperative period. Similar findings were reported by Mrinmoy Das, Manjushree Ray, Gauri Mukherjee in their study.

PONV is a distressing phenomenon occurring often after laparoscopic surgery. In our study, about $20 \%$ of patients complained of postoperative nausea and vomiting in the control group as compared to $3.33 \%$ in the study group (Table7).

Javaherfroosh F, M.Raza Pipelzadeh, Namazi M (2009) ${ }^{16}$ in their study showed that clonidine reduces postoperative nausea and vomiting following laparoscopic gynecological surgery.

\section{CONCLUSION:}

From our study, we derive the following conclusion:

- $\quad$ Preoperative medication with intravenous clonidine provides haemodynamic stability during laparoscopic surgery.

- $\quad$ Clonidine premedication blunts the pressor response to laryngoscopy

In addition to the above it was also observed that,

- $\quad$ Clonidine premedication has good sedative properties and analgesic sparing effect.

- $\quad$ Postoperative nausea and vomiting is reduced in clonidine premedicated patients.

- $\quad$ Clonidine prevents shivering in the postoperative period.

Thus, we conclude that intravenous clonidine premedication provides stable hemodynamics in laparoscopic surgeries.

\section{REFERENCES:}

1. Amirul Islam, Mozaffer Hossain, Akhtaruzzaman AKM, Shahera Khatun UH. Study on role of oral clonidine in laparoscopic cholecystectomy surgery: a comparative study. Journal of Bangladesh society of Anaesthesiologists, 2008; 21(1): 12-2.

2. Jean L. Joris, Jean Daniel Chiche, Jean-Luc M. Canivet, Nicolas J. Jacquet, Jean Jacques Y. Legros, and Maurice L. Lamy. Haemodynamic changes induced by laparoscopy and their endocrine correlates: effects of clonidine. J Am Coll Cardiol, 1998; 32:1389-1396.

3. Sunita Goel, Manju Sinha. Effect of oral clonidine premedication in patients undergoing laparoscopic surgery. Bombay Hospital Journal, 2006; 48(04): 587-591.

4. Laisalmi M, Koivusalo AM, Valta P, Tikkanen I, Lindgren L. Clonidine provides opioid-sparing effect, stable hemodynamics, and renal integrity during laparoscopic cholecystectomy. Surg Endosc 2001; 15: 1331-1335. 
5. Martina Aho, Lehtinen A-M., Laatikainen, Korttila K. Effects of intramuscular clonidine on haemodynamic and plasma $\beta$-endorphin responses to gynaecologic laparoscopy. Anesthesiology1990; 72: 797-802.

6. Mrinmoy Das, Manjushree Ray, Gauri Mukherjee. Haemodynamic changes during laparoscopic cholecystectomy: Effect of clonidine premedication. Indian J Anaesthesia, 2007; 51(3): 205210.

7. Peter J. Kulka, Michael Tyrba, Michael Zenz. Dose response effects of intravenous clonidine on stress response during induction of anaesthesia in coronary artery bypass graft patients. Anesth Analg, 1995; 80: 263-8.

8. Sia S. I.V. Clonidine prevents post-extradural shivering. British Journal of Anaesthesia, 1998; 81:145-146.

9. Stellato TA. History of laparoscopic surgery. Surg Clin North Am 1992; 72(5): 997-1002.

10. Vecchio R, MacFayden BV, Palazzo F. History of laparoscopic surgery. Pan Minerva Med, 2000; 42(1): 87-90.

11. Mealy K, Gallagher H, Barry M, Lennon F, Traynor O, Hyland J. Physiological and metabolic responses to open and laparoscopic cholecystectomy. Br J Surg 1992; 79: 1061-1064.

12. Westerband A, Van DE Water J, Amazallag M, Lebowitz PW, Chardavoyne R, Abou-Taleb. Cardiovascular changes during laparoscopic cholecystectomy. Surg Gynecol Obstet 1992; 175(6): 535-8.

13. Cunningham AJ, Turnem J et al. Transoesophageal echocardiographic assessment of haemodynamic function during laparoscopic cholecystectomy. Br J Anaesth 1993; 70: 621-625.

14. Wakizaka Y, Sano S, Koike Y, Nakanishi Y, Uchino J. Changes of arterial $\mathrm{CO}_{2}\left(\mathrm{PaCO}_{2}\right)$ and urine output by carbon dioxide insufflation of the peritoneal cavity during laparoscopic cholecystectomy. Nippon Geka Gakkai Zasshi, 1994; 95(5): 336-42.

15. O'Leary E, Hubbard K, Tormey W, Cunningham AJ. Laparoscopic cholecystectomy: haemodynamic and neuroendocrine responses after pneumoperitoneum and changes in position. Br J Anaesth 1996; 76: 640-644.

16. Javeherfroosh F, M Raza Pipelzadeh, Namazi M. Clonidine reduces postoperative nausea and vomiting in laparoscopic surgery. Pakistan J Med Sci, 2009; 25 (5): 782-785.

\section{AUTHORS:}

1. Sreeraghu G. M.

2. Hemanth Kumar J.

\section{PARTICULARS OF CONTRIBUTORS:}

1. Associate Professor, Department of Anesthesiology, Kempegowda Institute of Medical Sciences.

2. Assistant Professor, Department of Anesthesiology, Kempegowda Institute of Medical Sciences.

\section{NAME ADDRESS EMAIL ID OF THE CORRESPONDING AUTHOR: \\ Dr. Sreeraghu G. M, No. 57, MIG, $1^{\text {st }}$ Stage, KHB Colony, $3^{\text {rd }}$ Main Road, Basaveshwara Nagar, Bangalore - 560079. \\ E-mail: aimsraghu@yahoo.com}

Date of Submission: 26/01/2014. Date of Peer Review: 27/01/2014. Date of Acceptance: 07/02/2014. Date of Publishing: 19/02/2014. 